\title{
Thermodynamic Computations for Ion Exchange and Surface Protonation Reactions and the Implications for Acid Induced Contact Angle Evolution in Silica Rich Saline Aquifer Systems
}

\author{
Mumuni Amadu ${ }^{1}$, Adango Miadonye ${ }^{2}$ \\ ${ }^{1}$ Department of Process Engineering and Applied Sciences, Canada \\ ${ }^{2}$ Cape Breton University, Chemistry, School of Science Technology, Canada \\ Correspondence: Mumuni Amadu, Department of Process Engineering and Applied Sciences, Canada. \\ E-mail: mumuniamadu@hotmail.com or mm846771@dal.ca
}

\author{
Received: September 18, 2017 Accepted: October 8, 2017 Online Published: October 26, 2017 \\ doi:10.5539/ijc.v9n4p98 \\ URL: https://doi.org/10.5539/ijc.v9n4p98
}

\begin{abstract}
To reduce current high concentrations of anthropogenic greenhouse gases in the atmosphere to levels stipulated by the Intergovernmental Panel on Climate Change, geological sequestration has been universally proposed. On the basis of cost analysis and global availability, deep saline aquifers are the prime targets for most proposed commercial and pilot scale projects.

While the geological storage of anthropogenic carbon dioxide is expected to mitigate global warming, the technical aspects of the injection deserve to be considered for efficient injection projects. The water rock interaction phenomenon occurs due to carbonic acid generation which causes surface protonation reactions and has the potential to decrease water wettability of the system leading to enhanced water mobility and efficient gas injection. Therefore, for a saline aquifer rock with minerals capable of ion exchange reactions that consume solution protons, the wettability of such a system is likely to be preserved leading to reduced water mobility and poor gas injection. Generally, the extents to which surface protonation and ion exchange reactions occur depend on the free energy change of the reaction.

In this paper, we have carried out thermodynamic computations for the free energies of surface protonation and ion exchange reactions. Based on the values of computed free energies, which show that ion exchange reactions have lower free energies, we have discussed the wettability implications for geological storage in silica rich saline aquifer systems.
\end{abstract}

Keywords: Gibbs free energy, surface protonation, ion exchange, dielectric constant, wettability, contact angle

\section{Introduction}

As global warming, due to anthropogenic emission of carbon dioxide assumes alarming dimensions, the capture and geological isolation of this gas is considered necessary though there exist some limitations (Meer, Investigations regarding the storage of carbon dioxide in aquifers in the Netherlands, 1992). To isolate anthropogenic carbon dioxide at a rate commensurate with the rate at which it is being emitted, geologic repositories, notably saline aquifers have been endorsed by the Intergovernmental Panel on Climate Change (IPCC) (Bert, Davidson, Coninck, Manuela, \& Meyer, 2005). This is due to their promising global storage capacity (Szulczewski, MacMinn, Herzog, \& Juanes, 2012).

To be able to achieve efficient displacement of formation brine while storing large volumes of anthropogenic carbon, the wettability of the saline aquifer must be reduced to ensure enhanced relative mobility of resident formation brine. Generally, the relative permeability of a particular phase tends to decrease with increases in rock wetting with respect to that phase (Anderson, 1987). However, in view of the water rock interaction of carbon dioxide under subsurface condition (Matter \& Kelemen, 2009), the extent to which water wettability of the system can be altered depends on the types of digenetic minerals in the aquifer rock (Ketzer, et al., 2009). Siliciclastic (quartz rich) (Mcbride, A Classification of Common Sandstones, 1963) saline aquifer rocks with digenetic minerals such as glauconite and muscovite will have the potential for ion exchange reactions. In these reactions, hydrogen ions produced from the dissociation of carbonic acid, which are supposed to reduce formation water $\mathrm{pH}$ and reduce wettability (Jung \& Wan, 2012) will be exchanged for frame work potassium ions (Sainz-Diaz \& Coudros, 2001). On the other hand, monomineralic rocks such as those consisting of nearly $99 \%$ quartz and quartz cement will lack ion exchange reactions, which will enhance surface protonation reactions and increase solid-water interfacial tension leading to wettability reduction (Jung \& Wan, 2012). 
However, the extent to which ion exchange reactions and surface protonation reactions occur and compete for hydrogen ions produced from the dissociation of carbonic acid (McGrail, et al., 2006) will depend on the thermodynamic free energy of the reactions (Miller, Calcaterra, \& Closs, 1984). This is because, the thermodynamic free energy of a reaction measures the extent of feasibility. This means, depending on the values of the thermodynamic free energies, the order of feasibility of two possible reactions can be inferred. One reaction is where cation exchange reactions maintain wettability by $\mathrm{pH}$ buffering despite carbon dioxide dissolution. The other is where there is wettability reduction due to increases in hydrogen ion concentration from dissolved carbon dioxide. The order of feasibility of these reactions depends on the magnitudes of the free energies. Generally, the one with the most negative value will be more feasible. The objective of this paper is to carry out thermodynamic computations for surface protonation and ion exchange reactions and to use these as the bases for determining which of these reactions will be more feasible. The thermodynamic implications in light of contact angle evolution will be further discussed for saline aquifers under geological carbon storage.

\section{Literature Review}

\subsection{Relationship of Interfacial Free Energies to Contact Angle}

In the geologic environment, the system carbon dioxide-brine-solid/mineral surface is characterized by three distinct interfacial free energies or interfacial tensions. They are solid-liquid, solid-gas and gas-liquid interfacial free energies. These interfacial energies arise from intermolecular interactions at the interfaces $(\mathrm{Wu}, 1971)$ and they together control the wettability state of the system at a given $\mathrm{pH}$ of aqueous solution in light of Young's equation (Good, 1952). The wettability parameter of the system carbon dioxide-water-rock is the cosine of the contact angle which depends on the interfacial tension between the individual interfaces and it is given by Young's equation as: (Good, 1952):

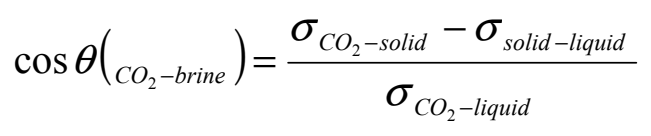

In which $\sigma_{\mathrm{CO}_{2} \text {-brine }}$ is the interfacial tension between water and carbon dioxide interface $\left[\mathrm{Nm}^{-1}\right], \sigma_{\mathrm{CO}_{2}-\text { solid }}$ is the interfacial tension between carbon dioxide and rock interface $[\mathrm{N} / \mathrm{m}]$ and $\sigma_{\text {solid-liquid }}$ is the interfacial tension between solid and water interface $[\mathrm{N} / \mathrm{m}]$ Equation 1 was deduced by Yong when he applied the condition of mechanical equilibrium along the point where the three interfaces meet the contact line. In principle, this equation expresses the ratio of the difference between two interfacial tensions or interfacial free energies $\left(\sigma_{\mathrm{CO}_{2} \text {-solid }}, \sigma_{\text {solid-liquid }}\right)$ to vapor-liquid interfacial tension and equates this to the cosine of the contact angle, which has a bearing on wettability. In the carbon dioxide-water-solid system, any changes in water $\mathrm{pH}$, which generate physiochemical reaction through water rock interaction will contribute to solidliquid interfacial tension changes to impact wettability. Changes in the other two surface tensions can also lead to wettability changes.

\section{Wettability Evolution during Geological Storage of Carbon Dioxide}

Different types of wettability regimes can be identified during geological storage of carbon dioxide in saline aquifers. One is where interfacial tension and wettability of the system remain constant. This is typical of deep saline aquifer geological storage where the pressure effect of gas solubility is neutralized by temperature effect. The second case is where wettability and interfacial tension change continuously. In the latter case, wettability changes mean changes in all the three interfacial tensions of the system or a change in any of them while others remain constant. The third case is where the wettability of the system immediately changes to a new wettability state determined by new values of all the three interfacial tensions and remains constant. The third case can be realized in carbon dioxide injection when the injected gas enters the formation under overburden pressures above $13 \mathrm{MPa}$. Figure 1 shows that for all formation brine salinities, geological sequestration of carbon dioxide at pressures typically above $13 \mathrm{MPa}$ will result in approximately constant carbon dioxide-brine interfacial tension. 


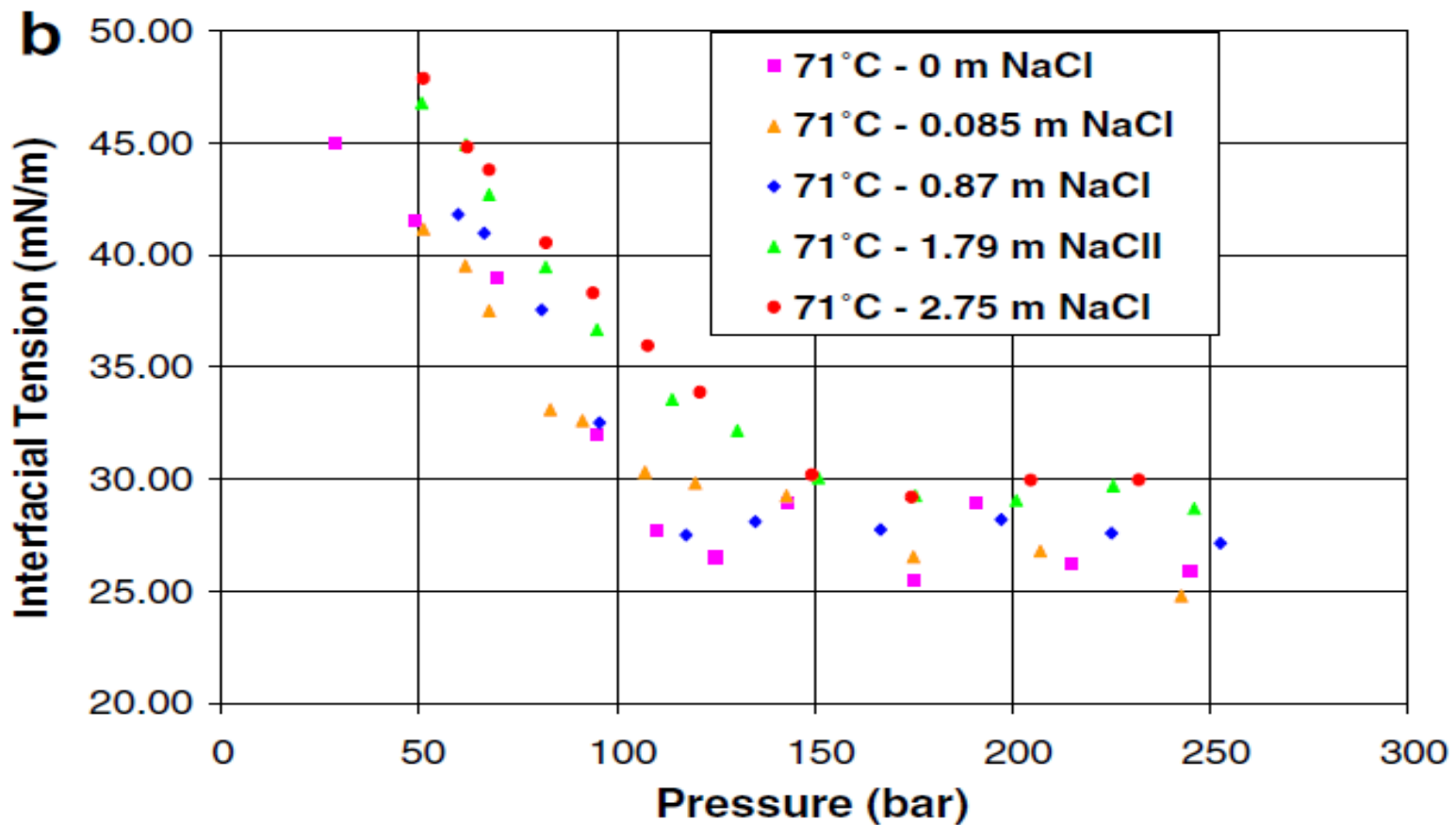

Figure 1. Interfacial tension between carbon dioxide and brine at different salinities versus pressure (Chalbaud et. al., 2009)

Under this condition, the solubility of carbon dioxide will be fixed by aquifer temperature, salinity and pressure. Solid-liquid interaction will occur at a given $\mathrm{pH}$ determined by the solubility of carbon dioxide (Søreide \& Whitson, 1992) at the prevailing aquifer temperature and salinity. Since gas solubility is constant, the interfacial tension between gas and water will be constant. Generally, it is the dissolved species of carbon dioxide that interact with the solid surface and not the gaseous phase. Therefore, solid-gas interfacial tension is also constant. Water rock-rock interactions between hydrogen ions produced from the dissociation of injected carbon dioxide will produce a new solid-liquid interfacial tension at the given $\mathrm{pH}$ of formation brine determined by carbon dioxide solubility. Therefore, for pressures more than 13 $\mathrm{MPa}$, where carbon dioxide-brine interfacial tension is practically constant (Chalbaud, et al., Interfacial tension measurements and wettability evaluation for geological CO 2 storage, 2009), the injection of carbon dioxide into a saline aquifer will result in a new wettability state of the system.

\section{Thermodynamic Computations}

\subsection{Thermodynamics of Protonatoion and Cation Exhnage Reactions}

The extent of reduction of the wettability of rock/mineral surface with regard to formation brine depends on the extent to which solid-liquid interfacial tension is increased by the adsorption of protons from carbonic acid dissociation. This is because, there are two contributions to solid-liquid interfacial tension. They are the contribution due to the free energy at the point of zero charge $\mathrm{pH}$ of solid surface and the contribution due to the free energy at the prevailing $\mathrm{pH}$ relative to the point of zero charge $\mathrm{pH}$ of solid surface (Chatelier, et al., 1995). For singificant contact angle increase, which corresponds to wettability decrease in light of Young's equation, surface protonation reaction ledaing to solid-liquid interfacial tension increase must be more feaseible compared the cation exchange reaction. Therefore, the thermodynamic free energies of proton adsorption and cation exchange reaction, which measure how far the reactions are from equilibrium and for that matter how feasible they will occur (Aagaard \& Helgeson, 1982) deserve to be considered and the following section will be devoted to that.

\subsection{Gibbs Free Energy Change for Surface Protonation Reaction}

Under formation water $\mathrm{pH}$ conditions typical of carbon geosequestration in sandstone saline aquifers (typically neutral) the surface of silica will be negatively charged.. The pertinent geochemical reaction is given as (Sverjensky, 1996):

$$
\equiv S_{i} O H \Leftrightarrow S_{i} O^{-}+H^{+}
$$

Hydrogen ions will be provided by the dissociation of carbonic acid. The Gibbs free energy for the reaction is given as (Sverjensky, 1996). 


$$
\Delta G_{r}^{o}=-2.3 R T \log K
$$

$\Delta G_{r}^{0}=$ Standard Gibbs free energy change for the reaction-KJ $/$ mole

$K$ = equilibrium constant for the reaction-mol/1

4.3 Thermodynamics of Ion Exchange

Cation exchange reaction involving potassium leaching from glauconite in sandstone under acidic conditions is described by the following reaction (Clearfield, 1988):

$$
A^{+}+B R=A R+B^{+}
$$

The Gibbs free energy change for this reaction is considered based on the following thermodynamic analyses (Clearfield, 1988):

For a monovalent ion that must be brought from the bulk of a dilute solution into contact with a fixed ionic grouping (of opposite charge) of an ion exchanger, two types of interactions have to be taken into consideration. They are the following:

1. The electrostatic interaction between the fixed grouping and the counterions or the exchanging ions

2. The free energy changes involving the hydration of the counterions and the fixed grouping

By regarding the fixed grouping and the counterions as being point charges, each at the center of an incompressible sphere, Eisemann (Eisenman, 1967), deduced that if the fixed grouping is anionic with radius $r_{f}$, then the electrostatic energy arising from the interaction with a cation $\mathrm{A}^{+}$of radius $r A^{+}$is given as:

$$
\Delta G^{o}=\frac{e^{2}}{r_{f}^{-}-r_{A}^{+}}
$$

Where e is the electronic charge

Similarly, the interaction of the fixed grouping with cation $\mathrm{B}+$ would give rise to a change in standard Gibbs free energy as:

$$
\Delta G^{o}=\frac{e^{2}}{r_{f}^{-}+r_{B}^{+}}
$$

The total standard Gibbs free energy change for the cation exchange reaction gives:

$$
\Delta G^{o}=-\frac{e^{2}}{r_{f}^{-}+r_{A}^{+}}-\frac{e^{2}}{r_{f}^{-}+r_{B}^{+}}
$$

To proceed further in the thermodynamic formulation, we have assumed that the free energy change due to hydration is related to the free energies of hydration of the ionic groups (Eisenman, 1967)

The total standard Gibbs free energy change for cation exchange reaction is then (Clearfield, 1988)

$$
\Delta G^{o}=\frac{e^{2}}{r_{f}^{-}+r_{A}^{+}}-\frac{e^{2}}{r_{f}^{-}+r_{B}^{+}}-\left(\Delta G_{A}^{+}-\Delta G_{B}^{+}\right)
$$

The free energy of hydration from Born's equation is given as (Jayaram, Sharp, \& Honig, 1989): 


$$
\Delta G_{h}=\frac{-q^{2}\left(1-\frac{1}{\varepsilon}\right)}{2 a}
$$

Where

$\Delta G_{h}=$ Gibbs free energy change of hydration

$q=$ charge on ion $-\mathrm{C}$

$\mathcal{E}=$ dielectric constant of solution

$\mathcal{E}=$ cavity radius-nm

\subsection{Modification}

To achieve the objective of this paper, Eisemann's equation will be modified. This is because, this equation considers a dilute solution where the dielectric constant is very big. The final equation for the total change in Gibbs free energy of ion exchange will be written in this paper as:

$$
\Delta G^{o}=\frac{e^{2}\left(1-\frac{1}{\varepsilon}\right)}{r_{f}^{-}+r_{A}^{+}}-\frac{e^{2}\left(1-\frac{1}{\varepsilon}\right)}{r_{f}^{-}+r_{B}^{+}}-\left(\Delta G_{A}^{+}-\Delta G_{B}^{+}\right)
$$

This modification takes account of the fact that under typical conditions of aquifer salinity (hypersaline conditions) for carbon dioxide injection, we have high salinities leading to a decrease in dielectric constant. From Born's equation Eq. 9, the reciprocal of the dielectric constant of brine under this condition is quite substantial to be neglected for the case of Eisemann's equation and hence Eq. 10.

\subsection{Final Equation}

By linking the electrostatic free energy of interaction in the hydration sphere to Avogadro's number, permittivity of vacuo and the dielectric constant of the medium, Eq. 10 for the total Gibb's free energy can be written by using the equation in (Bazhin, The Born Formula Describes Enthalpy of Ions Solvation, 2012) as:

$$
\Delta G^{o}=\frac{z^{2}}{8 \pi \varepsilon_{o}} \frac{e^{2}\left(1-\frac{1}{\varepsilon}\right)}{\left(r_{f}^{-}+r_{A}^{+}\right)}-\frac{z^{2}}{8 \pi \varepsilon_{o}} \frac{e^{2}\left(1-\frac{1}{\varepsilon}\right)}{\left(r_{f}^{-}+r_{B}^{+}\right)}-\left(\frac{z e^{2}}{2 a_{K^{+}} 8 \pi \varepsilon_{o}}\left(1-\frac{1}{\varepsilon}\right)-\frac{Z e^{2}}{2 a_{H^{+}} 8 \pi \varepsilon_{o}}\left(1-\frac{1}{\varepsilon}\right)\right)
$$

$z=$ valence of ion

$a_{K^{+}}=$radius of potassium ion-nm

$N_{A}=$ Avogadro's numbder-mol ${ }^{-1}$

$\mathcal{E}_{o}=$ permittivity of vacuo- $\mathrm{F} / \mathrm{m}$

\subsection{Salinity Effect on Dielectric Constant}

The dependence of static dielectric constant of formation brine on salinity is given as (Gadani, Rana, Bhatnagar, Prajapati, \& Vyas, 2012)

$$
\begin{gathered}
\mathcal{E}_{o}=(T, N)=\varepsilon_{o}(T, 0) a(N) \\
a(N)=1.000-0.2551 N+5.15 * 10^{-2} N^{2}-6.889 * 10^{-3} N^{3} \\
b(N T)=0.1463 * 10^{-2} N T+1.0000-0.04896 N-0.02967 N^{2}+5.644 * 10^{-3} N^{3}
\end{gathered}
$$




$$
\mathcal{E}_{o}(T, 0)=87.74-0.40008 T+9.398 * 10^{-4} T^{2}+1.410 * 10^{-6} T
$$

$\mathrm{T}$ is the temperature of the water in ${ }^{\circ} \mathrm{C}$ and $\mathrm{N}$ is the normality of the solution

\subsection{Calculation of Normality for a Case Study}

To contain anthropogenic carbon dioxide under supercritical conditions in the sedimentary basin, the threshold depth is 800 meters based on a mean geothermal gradient of $25{ }^{\circ} \mathrm{C}$ per kilometre. The mean concentration of chloride and sodium ions based on a strong regional digenetic imprint across Arkansas and North Louisiana are $171.7 \mathrm{gnd} 69 \mathrm{~g} / \mathrm{l}$ respectively (Moore \& Druckman, Burrial Diagenesis and Porosity Evolution, Upper Jurassic Smackover, Arkansas and Missouri, 1981), Table 3. The mean Total Dissolve Solute (TDS) is $279 \mathrm{~g} / 1$ (Moore \& Druckman, Burrial Diagenesis and Porosity Evolution, Upper Jurassic Smackover, Arkansas and Missouri, 1981). Using the equivalent sodium chloride concept (Moore et al., 1966), the percentage of chloride and sodium ions regarding TDS is 86 . The following ions will be used to represent formation brine composition:

$$
\begin{aligned}
& \mathrm{Na}=67 \mathrm{~g} / \mathrm{l} \\
& \mathrm{Mg}=3.4 \mathrm{~g} / 1 \\
& \mathrm{Cl}=171.7 \mathrm{~g} / 1 \\
& \mathrm{Ca}=34.5 \mathrm{~g} / 1
\end{aligned}
$$

Total dissolved solute is the sum $(276.6 \mathrm{~g} / \mathrm{l})$

The ratio of Calcium to magnesium is 10:1

By using the cation correction chart (Moore, Sasz, \& Whitney, 1966) the cation correction factor is 0.58 . The equivalent sodium chloride concentration is 0.58 multiplied by total dissolved solute which gives $160.4 \mathrm{~g} / 1$

This is equivalent to 2.77 moles per liter. The number of equivalent is calculated as the equivalent sodium chloride $(\mathrm{g} / \mathrm{l})$ divided by valence (1). The normality is thus $2.77 \mathrm{~mol} / \mathrm{l}$.

\subsection{Calculation of Dielectric Constant}

By assuming the threshold depth of $800 \mathrm{~m}$ for carbon geosequestration, the temperature of injected carbon dioxide is supercritical $\left(31^{\circ} \mathrm{C}\right)$. Application of Eq. 12 through Eq. 14 gives the dielectric constant of brine in a saline aquifer with the equivalent concentration of sodium chloride and temperature as $48.5 \mathrm{~F} / \mathrm{m}$.

\subsection{Thermodynamic Free Energy Computaion for Ion Exchange Reaction}

We assume an ion exchange between glauconite potassium and hydrogen ion from solution produced by the dissociation of carbonic acid formed during the injection of anthropogenic carbon dioxide into a glauconitic sandstone saline aquifer. In this approach, Eq. 11, for the total Gibbs free energy of ion exchange by glauconite frame work potassium and solution hydrogen is used. Calculated dielectric permitivity of saline aquifer brine is used with the value of Avagadros number $\left(6.23 * 10^{23} / \mathrm{mole}\right)$ and electronic charge $\left(6.22 * 10^{19} \mathrm{Coulomb}\right)$. The fixed ion in the glaoconite is assumed to be oxygen anion of radius of $0.145 \mathrm{~nm}$ (Lal, 2006). The radius of potassium and Hydrogen ions are taken as $\mathbf{0 . 1 3 8} \mathbf{~ n m}$ and $0.030 \mathrm{~nm}$, respectively (Marcus, 1991), the calculated Gibbs free energy change is $-7704 \mathrm{~kJ} / \mathrm{mo}$. In this calculation we assume the valency, $\mathrm{z}$, to be one.

\subsection{Thermodynamic Free Energy of Surface Protonation Reaction}

In this regard, we consider surface protonation reaction where there is proton adsorption on the surface of silica or quartz mineral of the saline aquifer as another proton sink (proton consumption reaction). This reaction will compete with the ion exchange reaction for proton consumption and the extent to which any of the reactions will proceed will depend on the free energy change of the reaction. Equation 5 for the Gibbs free energy change for the surface protonation reation is used with a value of the surface prototaion equilibrium constant being 7.5 (Sverjensky, 1996). The calculated free energy change is $-5078 \mathrm{Kj} / \mathrm{mol}$.

\section{Implications of Thermodynamic Free Energy of Protonation and Cation Exchange for Different Saline Aquifers}

To discuss the implications of the difference in thermodynamic free energies of cation exchange and surface protonation reactions on contact angle/wettability evolution for the system carbon dioxide-brine-mineral surface requires understanding the mechanism of interfacial free energy changes under conditions of formation brine $\mathrm{pH}$ evolution. The following sections will be devoted to this. 


\subsection{Mechanism of Interfacial Free Energy Change}

\subsubsection{Carbon dioxide Brine-Mineral System}

This system is characterized by water rock interaction (Matter, Takahashi, \& Goldberg, 2007). In light of interface chemistry, this reaction is characterized by protonation and deprotonation of surface hydroxyl functional groups in siliciclastic saline aquifers consisting predominantly of silica and subordinate amount of diagenetic minerals (Lanson, et al., 2002). The reactions can be described by the following equilibrium reaction (Duval, Mielczarski, Pokrovsky, Mielczarski, \& Ehrhardt, 2002):

$$
\begin{gathered}
\equiv S_{i} \mathrm{OH}+H^{+} \Leftrightarrow S_{i} \mathrm{OH}_{2}^{+} \\
\equiv S_{i} O H \Leftrightarrow S_{i} O^{-}+H^{+}
\end{gathered}
$$

In which $\equiv S_{i} O H$ is a neutral surface species, $S_{i} O^{-}$is a deprotonated surface species $\mathrm{H}^{+}$is hydrogen ion and $\equiv \mathrm{S}_{i} \mathrm{OH}_{2}^{+}$is protonated surface species.

The equilibrium constants for these reactions are given as:

$$
\begin{gathered}
K_{1}=\frac{\left[S_{i} O H_{2}^{+}\right]}{\left[S_{i} O H\right]\left[H^{+}\right]} \\
K_{2}=\frac{\left[S_{i} O^{-} \|\left[H^{+}\right]\right.}{\left[S_{i} O H\right]}
\end{gathered}
$$

In which $K_{1}$ is the equilibrium constant for the reaction described by Eq. 15 [mol/ l], $K_{2}$ is the equilibrium constant for the reaction described by Eq. $16\left[\mathrm{~mol} \mathrm{l}^{-}\right],\left[S_{i} O H\right]$ is the concentration of surface neutral species [mol/l], $\left[S_{i} O^{-}\right]$is the concentration of surface deprotonated species $\left[\mathrm{moll}^{-1}\right]$ and $\left[\mathrm{S}_{i} \mathrm{OH}_{2}^{+}\right]$is the concentration of surface protonated species $[\mathrm{mol} / \mathrm{l}]$ and $\left[\mathrm{H}^{+}\right\rfloor$is hydrogen ion concentration $[\mathrm{mol} / \mathrm{l}]$.

\subsection{Dependence of Solid-Liquid Interfacial Tension on pH from Molecular Theory}

Based on the molecular theory of interfacial tension, the solid-liquid interfacial tension is calculated as (Van Oss, Good, \& Chaudhury, 1988):

$$
\gamma_{S L}=\left(\left(\gamma_{S}^{L W}\right)^{1 / 2}-\left(\gamma_{L}^{L W}\right)^{1 / 2}\right)^{2}+2\left(\left(\gamma_{S}^{+} \gamma_{S}^{-}\right)^{1 / 2}+\left(\gamma_{L}^{+} \gamma_{L}^{-}\right)^{1 / 2}-\left(\gamma_{S}^{+} \gamma_{L}^{-}\right)^{1 / 2}-\left(\gamma_{S}^{-} \gamma_{L}^{+}\right)^{1 / 2}\right)
$$

In which $\gamma_{S L}$ is solid liquid interfacial tension [N/m], $\gamma_{S}^{L W}$ is dispersion force contribution to solid-liquid interfacial tension due to solid surface $[\mathrm{N} / \mathrm{m}], \quad \gamma_{L}^{L W}$ is the dispersion forces contribution to solid-liquid interfacial tension due to water $[\mathrm{N} / \mathrm{m}], \gamma_{S}^{-}$is the electron donor contribution to sold-liquid interfacial tension due to sold $[\mathrm{N} / \mathrm{m}], \gamma_{S}^{+}$is the electron acceptor contribution to solid-liquid interfacial tension due to solid $[\mathrm{N} / \mathrm{m}], \gamma_{L}^{+}$is the electron acceptor contribution to solid-liquid interfacial tension coming from liquid $[\mathrm{N} / \mathrm{m}]$ and $\gamma_{L}^{-}$is electron donor contribution to interfacial tension due to water $[\mathrm{N} / \mathrm{m}]$.

Under conditions typical of deep aquifer geologic storage (above $13 \mathrm{MPa}$ ) the $\mathrm{pH}$ of formation water is closer to neutral. Therefore, for a sandstone saline aquifer with predominant silica content, the surface charge of silica will be predominantly negative because the point of zero charge $\mathrm{pH}$ of this mineral is 3 (Kosmulski, 2006). Protonated surface 
species will be lacking and therefore Eq. 18 can be written as:

$$
\gamma_{S L}=\left(\left(\gamma_{S}^{L W}\right)^{1 / 2}-\left(\gamma_{L}^{L W}\right)^{1 / 2}\right)^{2}+2\left(\left(\gamma_{L}^{+} \gamma_{L}^{-}\right)^{1 / 2}-\left(\gamma_{S}^{-} \gamma_{L}^{+}\right)^{1 / 2}\right)
$$

For the system carbon dioxide-brine-mineral surface, solid-liquid interfacial tension will be $\mathrm{pH}$ dependent.

Generally, the electron acceptor and donor components of interfacial tension are related to the protonated and deprotonated species given in Eqs. 15 and 16. These species are $\mathrm{pH}$ dependent through the following equation (Glover, Meredith, Sammonds, \& Murrell, 1994):

$$
\begin{aligned}
& R_{p H}^{-}=\frac{\left[H^{+}\right]_{p z c}^{2}}{\left[H^{+}\right]_{p z c}^{2}+\left[H^{+}\right]^{2}} \\
& R_{p H}^{+}=1-R_{p H}^{-}=\frac{\left[H^{+}\right]_{p H}^{2}}{\left[H^{+}\right]_{p z c}^{2}+\left[H^{+}\right]_{p H}^{2}}
\end{aligned}
$$

In which $R_{p H}^{-}$is the fraction of surface sites available for the adsorption of positive species [-]. $R_{p H}^{-}$is the fraction of surface sites available for the adsorption of negative species, $\left[H^{+}\right] p z c$ is the hydrogen ion concentration of aqueous solution at the point of zero charge of rock surface moll $\left.{ }^{-1}\right]$ and $\left[H^{+}\right]$is the concentration of hydrogen ions of aqueous solution $[\mathrm{mol} / \mathrm{l}]$

To derive the $\mathrm{pH}$ dependence of solid-liquid interfacial tension we will assume here that the extent of electron donor contribution from solid will depend on the fraction of these sites available on the surface at a given $\mathrm{pH}$ of formation brine. The following equation will be written:

$$
\gamma_{S}^{-}=K R_{p H}^{-}=K \frac{\left[H^{+}\right]_{p z c}^{2}}{\left[H^{+}\right]_{p z c}^{2}+\left[H^{+}\right]^{2}}
$$

$\mathrm{K}=$ Constant of proportionality

For $\mathrm{pH}$ conditions, typical of carbon dioxide injection, Eq. 22 can be combined with Eq. 19 to give:

$$
\gamma_{S L}=\left(\left(\left(\gamma_{S}^{L W}\right)^{1 / 2}-\left(\gamma_{L}^{L W}\right)^{1 / 2}\right)^{2}+2\left(\left(\gamma_{L}^{+} \gamma_{L}^{-}\right)^{0.5}-\left(K\left(\frac{\left[H^{+}\right]_{P Z C}^{2}}{\left[H^{+}\right]_{P Z C}^{2}+\left[H^{+}\right]_{p H}^{2}}\right) \gamma_{L}^{+}\right)^{0.5}\right)\right)
$$

Equation 23 clearly shows the effect of hydrogen ion inputs on solid-liquid interfacial tension. Specifically, it shows that as hydrogen ion concentration increases due to $\mathrm{CO}_{2}$ dissolution, the expression involving hydrogen ions and the electron acceptor contribution to solid-liquid interfacial tension from liquid will decrease. The net effect is an increase in solid-liquid interfacial tension. The interfacial tension between gas and water is practically constant (Chalbaud, et al., 2009) at deeper depths of storage. Going by Young's equation, (Eq. 1), this corresponds to increase in contact angle and decrease wettability with increasing hydrogen ions or $\mathrm{pH}$ decreases.

\section{Implications for Different Saline Aquifer Rocks}

Saline aquifer rocks can be divided into two categories based on the ability of minerals found in the rocks to buffer formation water $\mathrm{pH}$. Normally, carbonate cement and mica minerals found in sandstones saline aquifers will tend to buffer formation water $\mathrm{pH}$ through hydrogen ion reaction with carbonate cement minerals (iron and magnesium carbonate) (Kharaka, et al., 2006) and through cation exchange reactions respectively (Lorenz, 1999). Any of these reactions has the capacity to deplete added hydrogen ions from carbonic acid dissociation leading to formation water $\mathrm{pH}$ buffering.

The other types of siliciclastic saline aquifers are the predominantly monomineralic or quartz arenites with very clean 
sands (Smith, Browne, Heinz, \& Wise, 1996). These aquifers will not be capable of formation water $\mathrm{pH}$ buffering and wettability changes during carbon dioxide injection into these aquifers will depend on variations of the three interfacial tensions found in Yong's equation. These saline aquifers will experience significant increases in solid-liquid interfacial tensions to cause significant contact angle changes, which will decrease water wetting of pore walls.

\section{Implications for Differences in Gibbs Free Energy Changes for Protonation and Cation Exchange Reaction}

The Gibbs free energy of a chmeical reactions measures how far it is from chemical equilibrium (Hellmann \& Tisserand, 2006). The farther the reaction is from equilibrium evidenced by low Gibbs free energy reaction, the more feasible it is. Comparison of thermodynamic Gibbs free energies of ion exchange and surface protonation reactions from section 4.8 and section 4.9 shows that the bigger negative value of the ion exchange reaction implies a greater feasibility of this reaction. Therefore, under the given aquifer temeprature and salinity conditions, ion exchange reaction will be more feasible compared to surface protonation reactions. The thermodynamic implication is that for sandstones with high proportions of glauconite or caly minerals, surface protonation reactions, which are the causes of solid-liquid interfacial tension increases will be less feasible compared to ion exchange reactions of the glauconites, which exchange frame work cation $\left(\mathrm{K}^{+}\right)$for solution hydrogen (Carroll, 1959). This means that interfacial tension increases, which are the causes of wettability reductions will be grossly impaired. By Young's equation, the wettability of the system will tend to be preserved during carbon dioxide injection as hydrogen ions from dissolved carbon dioxide are preferrably exchanged for potassium ions in octahedral framework of clay minerals, leading to formation water $\mathrm{pH}$ buffering as cation exchange fraction increases (Appelo, 1994)(Figure 1). Consequently, water relative mobility in such systems will be low. This is because local displacement efficiency depends on the fraction of resident brine that is contacted by injected carbon dioxide (Jessen, Kovscek, \& Orr Jr., 2005). The more wetting the aquifer is with reagrd to water, the smaller the fraction of brine contacted by injected gas.

Similarly, for sandstone saline aquifers where there are no glauconites, the absence of ion exchange reactions renders more hydrogen ions produced from the dissociation of carbonic acid available for surface protonation reactions. This will lead to significant increases in solid-liquid interfacial tension, which is the requirement for decreased water wettability of the system (Kim et al., 2012; Jung and Wan, 2012). leading to higher relative mobility of water. Generally, protonation reactions involving the interaction of hydrogen ions with surface negative species of deprotonated surface hydroxyl groups at $\mathrm{pH}$ above the point of zero charge $\mathrm{pH}$ of aquifer rock surface will promote water dewetting. For a predominatly sandstone saline aquifer, this will be predominant as carbon dioxide is injected. However, for a sandstone saline aquifer with significant proportion of caly minerals capable of cation exchnage reaction there will be comepetition between surface protonation reaction and cation exchnage reaction. The extent to which any of these reactions will occur will depend on the magnitude the free energy of reaction as revealed by our this paper.

\section{Conclusion}

Saline aquifer systems are mineralogically heterogeneous, cosnisting of predominant minerals with surbodinate amounts of other accessory minerals. Depending on the diagenetic imprint, a saline aquifer rock can have significant amount of accessory minerals. For siliciclastic saline aquifers with significant amount of clay minerals capable of formation water $\mathrm{pH}$ buffering reactions, competition between cation exchange and surface protonation reactions can impact wettability/contact angle evolution during carbon dioxide for geological storage. The extent to which cation exchage or surface protonation reaction will impact wettability evolution in such systems will depend on the thermodynamic free energy of the reaction. We have used thermodynamic approaches to calculate free energies of protonation and cation exchnage reactions under geological conditions of carbon storage. The following sum up the conclusions of this paper.

1. Thermodynamic calculations under conditions typical of geological carbon storage show that the free energy of cation exchange reactions is lower than that of protonation reaction.

2. On the basis of the dependence of reaction feasiblity on the magnitude Gibbs free energy, the lower value of this energy for cation exchange reaction means that it will be more feasible compared to surface protonation reaction.

3. For sandstone saline aquifers that are predominantly silica or silicicalstic, surface protonation reaction will be predomninant during carbon dioxide injection and this will promote silica dewetting with reagrd to water (Jung and Wan, 2012, Kim et al., 2012)

4. For sandstone saline aquifers with singificant proprtions of clay minerals, the greater feasibility of cation exchange reaction compared to surface protonation reaction will lead to $\mathrm{pH}$ buffering to enhance water wetting of silica surface (pore walls). These systems will be charcaterized by low water relative mobility 


\section{Aknowledgements}

We wish to acknowledge the immense contribution to our manuscript that came from the Document Delivery section of Dalhousie University library. The timely delivery of relevent literature made it possible to finish writing this manuscript on time.

\section{Reference}

Aagaard, P., \& Helgeson, H. C. (1982). Thermodynamic and kinetic constraints on reaction rates among minerals and aqueous solutions; I, Theoretical considerations. American journal of Science, 282(3), 237-285. https://doi.org/10.2475/ajs.282.3.237

Anderson, W. G. (1987). Wettability literature survey part 5: the effects of wettability on relative permeability. Journal of Petroleum Technology, 39(11), 1-453. https://doi.org/10.2118/16323-PA

Appelo, C. A. (1994). Cation and proton exchange, $\mathrm{pH}$ variations, and carbonate reactions in a freshening aquifer. Water Resources Research, 30(10), 2793-2805. https://doi.org/10.1029/94WR01048

Bazhin, N. (2012). The Born Formula Describes Enthalpy of Ions Solvation. International Scholarly Research Network, 2012(Article ID 204104). https://doi.org/10.5402/2012/204104

Bert, M., Davidson, O., Coninck, H. d., Manuela, L., \& Meyer, L. (2005). IPCC Special Report on Carbon Dioxide Capture and Storage. Prepared by Working Group III of the Intergovernmental Panel on Climate Change.

Carroll, D. (1959). Ion exchange in clays and other minerals. Geological Society of America Bulletin, 70(6), 749-779. https://doi.org/10.1130/0016-7606(1959)70[749:IEICAO]2.0.CO;2

Chalbaud, C., Robin, M., Lombard, J. M., Martin, F., Egermann, P., \& Bertin, H. (2009). Interfacial tension measurements and wettability evaluation for geological CO2 storage. Water Resources Volume, 32(1), 98-109. https://doi.org/10.1016/j.advwatres.2008.10.012

Chatelier, R. C., Drummond, C. J., Chan, D. Y., Vasic, Z. R., Gengenbach, T. R., \& Griesser, H. J. (1995). Theory of contact angles and the free energy of formation of ionizable surfaces: application to heptylamine radio-frequency plasma-deposited films. Langmuir, 11(10), 4122-4128. https://doi.org/10.1021/la00010a078

Clearfield, A. (1988, October 1). Role of Ion Exchange in Solid-State Chemistry. Chem. Rev, 88, 125-148. https://doi.org/10.1021/cr00083a007

Duval, Y., Mielczarski, J. A., Pokrovsky, O. S., Mielczarski, E., \& Ehrhardt, J. J. (2002). Evidence of the existence of three types of species at the quartz-aqueous solution interface at $\mathrm{pH}$ 0-10: XPS surface group quantification and surface complexation modeling. The Journal of Physical Chemistry B, 106(11), 2937-2945. https://doi.org/10.1021/jp012818s

Eisenman, G. (1967). Glass Electrodes for Hydrogen and Other Cations. Marcel Dekker.

Gadani, D. H., Rana, V. A., Bhatnagar, S. P., Prajapati, A. N., \& Vyas, A. D. (2012, June). Effect of Salinity on the Dielectric Properties of Water. Indian Journal of Pure and Applied Science, 50(6), 405-410.

Glover, P. W., Meredith, P. G., Sammonds, P. R., \& Murrell, S. A. (1994). Ionic surface electrical conductivity in sandstone . Journal of Geophysical Research: Solid Earth, 99(B11), 21635-21650. https://doi.org/10.1029/94JB01474

Good, R. J. (1952). A Thermodynamic Derivation of Wenzel's Modification of Young's Equation for Contact Angles; Together with a Theory of Hysteresis1. Journal of the American Chemical Society, 74(20), 5041-5042. https://doi.org/10.1021/ja01140a014

Hellmann, R., \& Tisserand, D. (2006, January 15). Dissolution kinetics as a function of the Gibbs free energy of reaction: An experimental study based on albite feldspar. Geochimica et Cosmochimica Acta, 70(2), 364-383. https://doi.org/10.1016/j.gca.2005.10.007

Jayaram, B. F., Sharp, K., \& Honig, B. (1989, May). Free Energy Calculations of Ion Hydration: An Analysis of the Born Model in Terms of microscopic simulations. J. Phys. Chem., 93(10), 4320-4327. https://doi.org/10.1021/j100347a081

Jessen, K., Kovscek, A. R., \& Orr Jr., F. M. (2005, January). Increasing CO2 storage in oil recovery. Energy Conversion and Management, 46(2), 293-311.

Jung, J. W., \& Wan, J. (2012). Supercritical CO2 and ionic strength effects on wettability of silica surfaces: Equilibrium contact angle measurements. Energy \& Fuels, 26(9), 6053-6059. https://doi.org/10.1021/ef300913t 
Ketzer, J. M., Iglesias, R., Einloft, S., Dullius, J., Ligabue, R., \& De Lima, V. (2009). Water-rock-CO 2 interactions in saline aquifers aimed for carbon dioxide storage: experimental and numerical modeling studies of the Rio Bonito Formation (Permian). Applied geochemistry, 24(5), 760-767. https://doi.org/10.1016/j.apgeochem.2009.01.001

Kharaka, Y. K., Cole, D. R., Hovorka, S. D., Gunter, W. D., Knauss, K. G., \& Freifeld, B. M. (2006). Gas-water-rock interactions in Frio Formation following $\mathrm{CO} 2$ injection: Implications for the storage of greenhouse gases in sedimentary basins. Geology, 34(7), 577-580. https://doi.org/10.1130/G22357.1

Kim, Y., Wan, J., Kneafsey, T. J., \& Tokunaga, T. K. (2012). Dewetting of silica surfaces upon reactions with supercritical $\mathrm{CO} 2$ and brine: pore-scale studies in micromodels. Environmental science \& technology, 46(7), 4228-4235. https://doi.org/10.1021/es204096w

Kosmulski, M. (2006). pH-dependent surface charging and points of zero charge III. Update. Journal of Colloid and Interface Science, 298, 730-741. https://doi.org/10.1016/j.jcis.2006.01.003

Lal, R. (2006). Encyclopedia of Soil Science: Second Edition Volume 1. Taylor and Francis Group .

Lanson, B., Beaufort, D., Berger, G., Bauer, A., Cassagnabere, A., \& Meunier, A. (2002). Authigenic kaolin and illitic minerals during burial diagenesis of sandstones: a review. Clay minerals, 37(1), 1-22. https://doi.org/10.1180/0009855023710014

Lorenz, P. M. (1999). Determination of the cation exchange capacity (CEC) of clay minerals using the complexes of copper (II) ion with triethylenetetramine and tetraethylenepentamine. Clays Clay Miner, 47, 386-388. https://doi.org/10.1346/CCMN.1999.0470315

Marcus, Y. (1991). Thermodynamkics of Solvation of Ions Part 5.-Gibbs Free Energy of Hydration at 298.15 K. $J$. Chem. Soc. Faraday Trans, 83, 2995-2999. https://doi.org/10.1039/FT9918702995

Matter, J. M., \& Kelemen, P. B. (2009, November 8). Permanent storage of carbon dioxide in geological reservoirs by mineral carbonation. Nature Geoscience, 2, 837-841. https://doi.org/10.1038/ngeo683

Matter, J. M., Takahashi, T., \& Goldberg, D. (2007, February). Experimental evaluation of in situ CO2-water-rock reactions during $\mathrm{CO} 2$ injection in basaltic rocks: Implications for geological $\mathrm{CO} 2$ sequestration. Geochemisty, Geophysics and Geoasystems, 8(2).

Mcbride, E. F. (1963). A Classification of Common Sandstones. Journal of Sedimentary Petrology, 33(3), 664-669.

McGrail, P., Schaef, H. T., Ho, A. M., Chien, Y. J., Dooley, J. J., \& Davidson, C. L. (2006, December 2). Potential for carbon dioxide sequestration in flood basalts. Journal of Geophysical Research: Solid Earth (1978-2012), 111(B12), 1-13.

Meer, L. V. (1992, May-August). Investigations regarding the storage of carbon dioxide in aquifers in the Netherlands. Energy Conversion and Management, 33(5-8), 611-618. https://doi.org/10.1016/0196-8904(92)90063-3

Miller, J. R., Calcaterra, L. T., \& Closs, G. L. (1984). Intramolecular long-distance electron transfer in radical anions. The effects of free energy and solvent on the reaction rates. J. Am. Chem. Soc., 106(10), 3047-3049. https://doi.org/10.1021/ja00322a058

Moore, C. H., \& Druckman, Y. (1981, April). Burrial Diagenesis and Porosity Evolution, Upper Jurassic Smackover, Arkansas and Missouri. APPG Bullettin, 65(4), 597-628.

Moore, E. J., Sasz, S. E., \& Whitney, B. F. (1966, March). Determining Formation Water Resistivity From Chemical Analysis. Journal of Petroleum Technology, 18(3), 373-376. https://doi.org/10.2118/1337-PA

Sainz-Diaz, C., \& Coudros, J. H. L. (2001). Analysis of Cation Distribution in the Octahedral Sheets of Dioctahedral 2:1 Phyllosilicates by Using Inverse Monte Methods. Phy Chem. Min., 200(28), 445-454.

Smith, P. S., Browne, S. V., Heinz, T. J., \& Wise, W. V. (1996). Drilling fluid design to prevent formation damage in high permeability quartz arenite sandstones. In SPE Annual Technical Conference and Exhibition. Society of Petroleum Engineer. https://doi.org/10.2118/36430-MS

Søreide, I., \& Whitson, C. H. (1992). Peng-Robinson predictions for hydrocarbons, CO2, N2, and H2 S with pure water and $\mathrm{NaCI}$ brine. Fluid Phase Equilibria, 77, 217-240. https://doi.org/10.1016/0378-3812(92)85105-H

Sverjensky, D. A. (1996, October). Theoretical Prediction of Single-site Surface-Protonation Constants for Oxides and $\begin{array}{lllll}\text { and Silicates. Geochimica et } & \text { Cosnochimica }\end{array}$ https://doi.org/10.1016/0016-7037(96)00207-4

Szulczewski, M. L., MacMinn, C. W., Herzog, H. J., \& Juanes, R. (2012). Lifetime of carbon capture and storage as a climate-change mitigation technology. Proceedings of the National Academy of Sciences, 109, 5185-5189. 
https://doi.org/10.1073/pnas.1115347109

Van Oss, C. J., Good, R. J., \& Chaudhury, M. K. (1988). Additive and nonadditive surface tension components and the interpretation of contact angles. Langmuir, 4(4), 884-891. https://doi.org/10.1021/la00082a018

Wu, S. (1971). Calculation of interfacial tension in polymer systems. Wu, S. (1971, January). Calculation of interfacial tension in polymer systems. In Journal of Polymer Science: Polymer Symposia (pp. 19-30). In Journal of Polymer Science. https://doi.org/10.1002/polc.5070340105

\section{Copyrights}

Copyright for this article is retained by the author(s), with first publication rights granted to the journal.

This is an open-access article distributed under the terms and conditions of the Creative Commons Attribution license (http://creativecommons.org/licenses/by/4.0/). 